Please do not remove this page

RMIT

UNIVERSITY

\title{
Investigation of gas sensors for cabin air quality monitoring
}

Galatsis, Kosmas; Wlodarski, Wojciech; Kalantar Zadeh, Kourosh; Trinchi, Adrian

https://researchrepository.rmit.edu.au/esploro/outputs/9921863976601341/filesAndLinks?institution=61RMIT_INST\&index=null

Galatsis, K., Wlodarski, W., Kalantar Zadeh, K., \& Trinchi, A. (2002). Investigation of gas sensors for cabin air quality monitoring. COMMAD 2002 Proceedings, 229-232.

https://doi.org/10.1109/COMMAD.2002.1237234

Document Version: Published Version

Published Version: https://doi.org/10.1109/COMMAD.2002.1237234

Repository homepage: https://researchrepository.rmit.edu.au

(c) 2002 IEEE. Personal use of this material is permitted. However, permission to reprint/republish this material for advertising or promotional purposes or for creating new collective works for resale or redistribution to servers or lists, or to reuse any copyrighted component of this work in other works must be obtained from the IEEE.

Downloaded On 2023/04/26 16:26:50 +1000 


\title{
INVESTIGATION OF GAS SENSORS FOR VEHICLE CABIN AIR QUALITY MONITORING
}

\author{
K. Galatsis, W. Wlodarski, K. Kalantar-Zadeh and A. Trinchi \\ Sensor Technology Laboratory, School of Electrical and Computer Engineering, \\ RMIT University, GPO Box 2476V, Melbourne 3001, AUSTRALIA \\ Phone: +61 39925 3690, Fax: +61 39925 2007, E-Mail: koz@ieee.org
}

\begin{abstract}
Car cabin air quality monitoring can effectively be analysed using metal oxide semiconducting (MOS) gas sensors. In this paper, commercially available gas sensors are compared with fabricated $\mathrm{MoO}_{3}-\mathrm{TiO}_{2}$ and $\mathrm{MoO}_{3}$ $\mathrm{WO}_{3}$ thin films. The laboratory tests showed that the $\mathrm{MoO}_{3}$ based sensors possessed comparable gas sensing properties. The $\mathrm{MoO}_{3}(75 \%)-\mathrm{TiO}_{2}(25 \%)$ sensor has a response $74 \%$ higher relative to the best commercial sensor tested.
\end{abstract}

\section{INTRODUCTION}

Gas sensors are increasingly used for automotive applications. The need to monitor several gases such as carbon monoxide $(\mathrm{CO})$ and nitrogen oxides $\left(\mathrm{NO}_{\mathbf{x}}\right)$ is required to ensure complete vehicle occupant comfort and safety by automatically controlling the Heating Ventilation and Air Conditioning (HVAC) system. According to Strategy Analytics (Boston, MA, USA [1]) the demand for sensors used in automotive HVAC systems has totalled 25.6 million units in 1999 and is projected to increase at a $21.3 \%$ compound annual rate to reach 67.1 million units in 2004. This high demand of gas sensors in this market segment has motivated our laboratory to focus on fabricating and developing innovative HVAC gas sensors and systems. However, since 1999 our research endeavours [4-6] have not only focused on air quality sensors to improve vehicle occupant comfort via HVAC control. Our research focuses on improving automotive safety by developing sensors and systems to prevent driver fatigue caused by poor cabin air quality and exhaust gas suicides.

\section{VEHICLE CABIN AIR QUALITY SENSORS}

The aim of this paper is to compare gas sensors towards exhaust gas in order to determine gas sensor candidates for the development of a cabin air quality system. Indeed, a host of gas sensors exist which could be used within a vehicle cabin air quality monitor. However, to analyse the options systematically, first the comparison of the three predominant sensing technologies, capable of detecting gases such as carbon monoxide (CO), is required to be undertaken. First, are the common Metal Oxide Semiconductor (MOS) gas sensors. These sensors are heated, causing $\mathrm{CO}$ to react at with the surface of the metal oxide film changing the semiconductor's conductivity proportional to the $\mathrm{CO}$ concentration. Second, are the Electrochemical gas sensors. Electrodes are placed in contact with an liquid electrolyte to form an electrochemical sensor. The gas diffuses and reacts with the working electrode, changing its potential proportional to the gas concentration. And thirdly, are Optical sensors where the optical sensing element undergoes light transmission changes when exposed to the target gas. Table 1 compares the technologies against seven criteria, which are of paramount importance in developing an air quality monitor for the automotive industry. 
Table 1: Comparison of various gas sensing technologies for vehicle cabin air quality monitors.

\begin{tabular}{lccc}
\hline & Optical & Electrochemical & MOS \\
\hline Cost (\#100) & $\$ 100$ 's & \$5 US & $\$ 15$ US \\
Life time & $>10$ years & 2 years & $>10$ years \\
Sensitivity & Excellent & Very Good & Good \\
Selectivity & Excellent & Very Good & Good \\
Response Time & Good & Good & Good \\
Size (relative) & Large & Medium & Small \\
Ease of use & Adequate & Excellent & Excellent \\
\hline
\end{tabular}

From Table 1 it is clearly evident that MOS gas sensors are the most promising practical gas sensors to be employed within an air quality monitor. MOS sensors are already used for HVAC control by companies such as Paragon (Germany), Valeo (France), Casco (USA), Delphi (USA) and First Technology (USA). These companies make use of commercially available MOS gas sensors from companies such as Figaro (Japan), Microsens (Switzerland), Steinel (Germany), MicroChemical (Swtizerland), Capteur (U.K.), FIS Technology (Japan), General Eastern (USA), UST (Germany) and Nemoto (Japan). Selectivity, still remains to be the main shortfall of nearly all commercially available MOS gas sensors, however this attribute is continuously improving.

Three commercially available gas sensors were selected to be tested and compared. The three commercial sensors selected for comparison were:

- $\quad$ Figaro, Japan, TGS-2442

- $\quad$ Capteur, U.K., GLG-0710

- MicroChemical, Switzerland, MiCS-4512

Our research efforts have also focused on developing stable gas sensor films for various applications [2-3]. Materials such as $\mathrm{MoO}_{3}, \mathrm{WO}_{3}$ and $\mathrm{TiO}_{2}$ have been employed to fabricate exotic binary metal oxides such as $\mathrm{MoO}_{3}-\mathrm{WO}_{3}$ and $\mathrm{MoO}_{3}-\mathrm{TiO}_{2}$ thin films. These films have been shown to possess promising gas sensing characteristics, and have therefore also been included in the comparison.

\section{EXPERIMENTAL}

A microprocessor based sensor array system was specifically developed to simultaneously compare four sensors. A PC was connected to the system via a RS-232 interface used for datalogging. The system transforms the analog sensor signals to digital format via a A-D converter. The system samples the sensor once per second.

$\mathrm{MoO}_{3}-\mathrm{TiO}_{2}$ and $\mathrm{MoO}_{3}-\mathrm{WO}_{3}$ thin films based sensors were fabricated using the sol-gel process. Films were spun onto conductometric alumina based transducers and were then annealed at $500^{\circ} \mathrm{C}$ for 1 hour [2-3]. The commercial sensors were operated as specified by the manufacturer's datasheets. The sensors from Capteur, MicroChemical were operated in a DC fashion, while the Figaro sensor was pulsed. The Mo-Ti / Mo-W sensors were operated at $300^{\circ} \mathrm{C}$ by passing a DC current through the transducer's heater element.

The sensor PCB is connected to the main microprocessor via a ribbon cable. The airflow passing through the sensor chamber was regulated at $0.3 \mathrm{LPM}$. An air pump was used at room temperature with a relative humidity at $30 \mathrm{RH} \%$ to provide the positive pressure. Exhaust gas was confined in a gasbag. This was delivered into the gas test system via a DC diaphragm pump. 


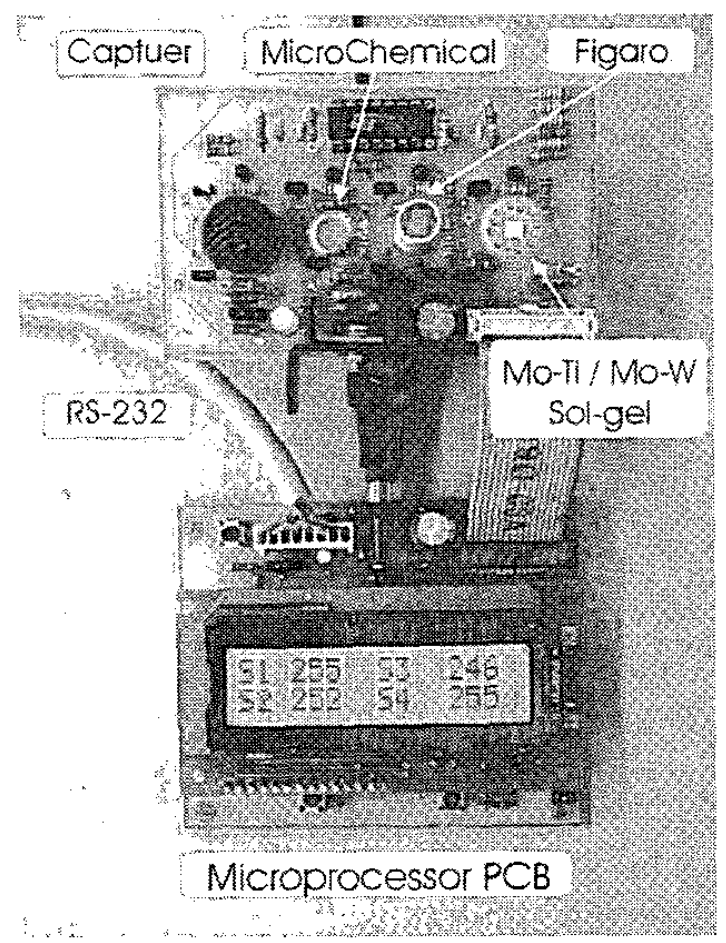

Fig. 1. The electronics system developed to compare 4 different MOS gas sensors.

\section{RESULTS}

The sensors were operated at room temperature for 24 hours whilst air at a flow rate of 0.3 LPM passed through the gas chamber before any testing proceeded. The sensors were exposed to 2-minute pulses of exhaust gas, following a 3-minute exposure to pure air. Figure 2 shows the response of the sensors. The sensor's "response" is a ratio of sensor resistance (air) to sensor resistance (gas).

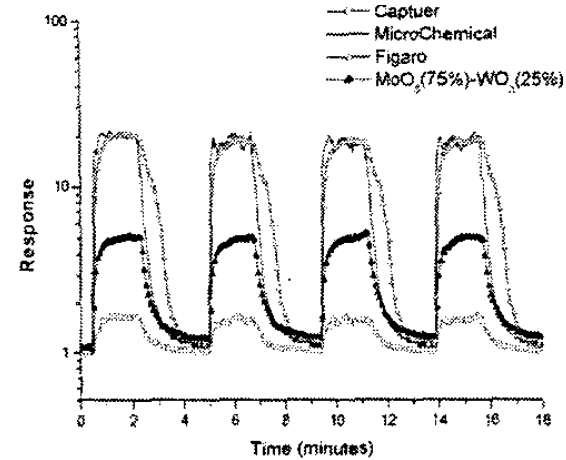

(a)

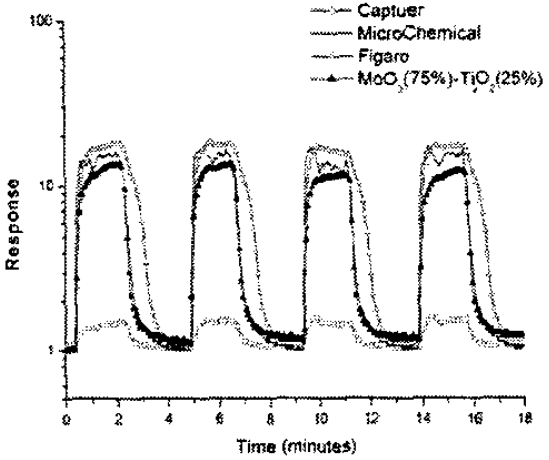

(b)

Fig. 2: Gasoline exhaust gas response of (a) $\mathrm{MoO}_{3}(75 \%)-\mathrm{WO}_{3}(25 \%)$ and (b) $\mathrm{MoO}_{3}(75 \%)-\mathrm{TiO}_{2}(25 \%)$ compared to commercially available sensors.

First observations of the responses show the sensors are stable and possess repeatable sensing characteristics, this is a very important attribute when considering practical use of MOS gas sensors. Throughout the tests, both MicroChemical and Figaro sensors possessed the highest response magnitudes. Figaro exhibited a slow response 
time as a result of the sensor's filter arrangement. The MicroChemical sensor possessed a high response magnitude together with an extremely fast response time of 15 seconds. The $\mathrm{MoO}_{3}(75 \%)-\mathrm{WO}_{3}(25 \%)$ sensor had a response fraction of $27 \%$ compared to the MicroChemical sensor. The $\mathrm{MoO}_{3}(75 \%)-\mathrm{TiO}_{2}(25 \%)$ sensor has a response fraction of $74 \%$ relative to the response of the Figaro sensor.

Fig. 3 shows the response of the $\mathrm{MoO}_{3}(25 \%)-\mathrm{WO}_{3}(75 \%)$ sensor during a simulated suicide attempt. Exhaust was redirected from into the vehicle cabin resulting in a build up of exhaust gas, as would occur during a suicide attempt.

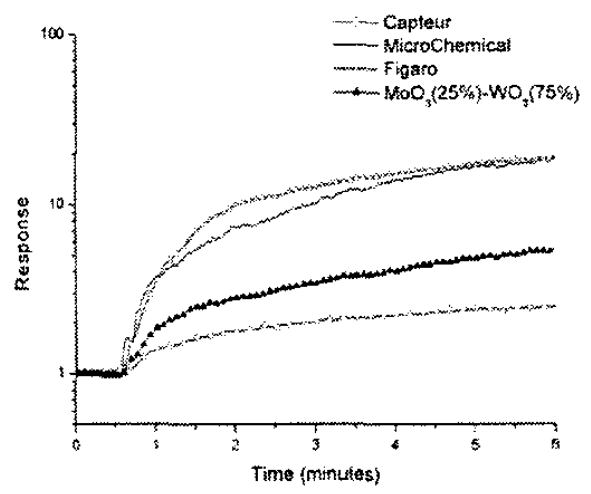

Fig. 3. Exhaust gas suicide simulation response of $\mathrm{MoO}_{3}(25 \%)-\mathrm{WO}_{3}(75 \%)$ sensor.

\section{CONCLUSIONS}

A large array of gas sensors exist which could be used for vehicle cabin air quality monitors. All sensors tested possessed stable, reliable and repeatable gas sensing characteristics. Although their selectivity properties were not scrutinised, they nevertheless successfully responded to exhaust gas and therefore could be satisfactorily used within vehicle air quality monitors. However, it must be mentioned that MOS sensors are susceptible to poisoning especially in an oxidising environment (i.e. towards ozone or $\mathrm{NO}_{2}$ ) and also are sensitive to ambient temperature and humidity effects. Hence our future research will investigate the $\mathrm{CO}, \mathrm{HC}, \mathrm{NO}_{2}$, temperature and humidity effects of these sensors.

\section{REFERENCES}

1. Sensor Business Digest, http://www.sensauto.com/sbd.html, 2002.

2. K.Galatsis, Y.X.Li, W.Wlodarski, E.Comini, G.Faglia, G.Sberveglieri, Semiconductor $\mathrm{MoO}_{3}-\mathrm{TiO}_{2}$ Thin Film Gas Sensor, Sensors and Actuators B, 77 (2001), $474-477$.

3. K.Galatsis, Y.X.Li, W.Wlodarski, Sol-gel prepared $\mathrm{MoO}_{3}-\mathrm{WO}_{3}$ Thin Films for Gas Sensing, Sensors and Actuators B, 77 (2001), 478-483.

4. K.Galatsis, W.Wlodarksi, B.Wells, and S.McDonald, "Vehicle Cabin Air Quality monitor for fatigue and suicide prevention," 2000 SAE Transactions - Journal of Passenger Car - Mechanical Systems. September 2001.

5. K.Galatsis, W.Wlodarski, Y.X.Li, and K.Kalantar-zadeh, "Ventilation control for improved cabin air quality and vehicle safety," The 2001 Spring IEEE Semiannual Vehicular Technology Conference, May 2001, Rhodes, Greece.

6. K. Galatsis, Y. Li, W. Wlodarski, E. Comini, G. Sberveglieri, "Binary Metal Oxide $\mathrm{MoO}_{3}-\mathrm{TiO}_{2}$ and $\mathrm{MoO}_{3}$ $\mathrm{WO}_{2}$ Thin Film Gas Sensors for Environmental Applications" International workshop on new developments on sensors for environmental control, Lecce, Italy, May $27^{\text {th }}$ to $29^{\text {th }}, 2002$. 